\title{
CUIDADOS PALIATIVOS NO DOMICÍLIO: RELATANDO A EXPERIÊNCIA DOS ENCONTROS
}

\author{
PALLIATIVE CARE AT HOME: REPORTING THE EXPERIENCE OF \\ MEETINGS
}

\begin{abstract}
Lilian Zielke Hesler ${ }^{1}$, Katryn Corrêa da Silva ${ }^{1}$, Luís Gustavo Mello dos Santos ${ }^{1}$, Luciane Bertolazzi de Moura ${ }^{1}$, Maira Bagatini ${ }^{2}$, Kelly Cristina Meller Sangoi ${ }^{1}$, Daniela Pereira Gonzalez ${ }^{1}$

${ }^{1}$ Universidade Regional Integrada do Alto Uruguai e das Missões (URI), Santo Ângelo, RS, Brasil; ${ }^{2}$ Secretaria Municipal de Saúde do Município de Santo Ângelo, RS, Brasil.
\end{abstract}

\section{RESUMO}

Introduçáo: O Cuidado Paliativo é composto por açóes que possuem a finalidade de ofertar uma morte digna ao paciente, adaptando formas de cuidar após não haver mais resposta ao tratamento farmacológico curativo. Objetivo: relatar a experiência vivenciada pelos integrantes do eixo cuidados paliativos no domicílio do Programa de Educação pelo Trabalho e para a Saúde (PET - Saúde/Interprofissionalidade), tendo ênfase os encontros semanais do grupo. Metodologia: trata-se de um estudo descritivo com abordagem qualitativa, do tipo relato de experiência. A experiência dos encontros foi vivenciada por tutores, preceptores e acadêmicos bolsistas e voluntários do projeto. Os encontros ocorriam semanalmente, em uma sala de aula da Universidade Regional Integrada do Alto Uruguai e das Missōes, Campus Santo Ângelo. Para os encontros optou-se em utilizar o método roda de conversa, facilitando o diálogo e participação de todos. Resultados: Além dos encontros semanais, o grupo também promoveu um ciclo de palestras sobre a temática, visita técnica nos serviços de saúde do município com o intuito de desenvolver um diagnóstico situacional e visitas domiciliares aos pacientes em cuidados paliativos. Conclusáo: Foi notório o quanto o projeto PET - Saúde/Interprofissionalidade proporciona vivências ímpares aos tutores, preceptores e acadêmicos.

Descritores: Cuidados Paliativos; Morte; Educação Interprofissional; Visita Domiciliar.

\section{RESUMEN}

Los cuidados paliativos se componen de acciones que tienenel propósito de ofrecer una muerte digna al paciente, adaptando formas de atención después de que no haya más respuesta al tratamiento farmacológico curativo. Este trabajo tiene como objetivo informar la experiencia de los membros del eje de cuidados paliativos e nelhogarenel Programa de Educación a través del Trabajo y la Salud (PET - Salud/Interprofesionalidad), conén fasisen las reuniones grupales semanales. Este es um estúdio descriptivo con un enfoque cualitativo, un tipo de informe de experiencia. La 
experiencia de las reuniones fue experimentada por tutores, preceptores y becarios académicos y voluntários del proyecto. Las reuniones tienen lugar semanalmente, en un aula de la Universidad Regional Integrada do Alto Uruguai y Missóes, Campus Santo Ângelo. Para las reuniones, optamos por utilizar el método de la rueda de conversación, facilitando el diálogo y la participación de todos. Además de las reuniones semanales, el grupo también promueve un ciclo de conferencias sobre el tema, una visita técnica a los servicios de salud del municipio para desarrollar un diagnóstico situacional y visitas domiciliarias a pacientes en cuidados paliativos. Era notório cuánto el proyecto PET - Saludl Interprofesional brinda experiencias únicas para tutores, tutores y académicos.

Descriptores: cuidados paliativos; muerte; visista a casa; educación interprofesional.

\section{INTRODUÇÁO}

Os Cuidados Paliativos (CP) estão presentes nos casos de adoecimento que exigem maior comprometimento dos profissionais para com os pacientes e seus familiares. $\mathrm{O}$ cuidado disponibilizado deve ser centrado na pessoa e não na doença, pois se trata de um estágio em que os problemas de saúde ameaçam a continuidade da vida e não possuem possibilidade de cura. Assim, o bem-estar físico, emocional e espiritual, ganham maior espaço nos CP. ${ }^{1}$

A Organização Mundial da Saúde (OMS) definiu que, os cuidados voltados para pacientes em estado de terminalidade, fora da possibilidade de cura ou que ameaçam a vida são chamados de cuidados paliativos. Esses cuidados devem abordar e promover a qualidade de vida dos pacientes e familiares, buscando a prevenção e o alívio do sofrimento dos mesmos. ${ }^{2}$

Tendo em vista que os CP são um conjunto de ações que possuem a finalidade de ofertar uma morte digna ao paciente, adaptando formas de cuidar após não haver mais resposta ao tratamento medicamentoso, a aceitação do final do ciclo da vida, é um assunto que envolve inúmeras questóes, como por exemplo, a idade, questão social, reaçóes psicológicas, entre outros fatores que dificultam esse processo e tendem a ser melhor trabalhado pelos profissionais que estáo nesse campo de atuação, inseridos nos $\mathrm{CP}^{3}$

Na década de 1980, os CP eram voltados somente a pacientes com câncer, porém, atualmente é notável a crescente necessidade dos CP em doenças variadas como, a síndrome da imunodeficiência adquirida, a insuficiência cardíaca congestiva, doenças neurológicas, respiratórias e outras crônico-degenerativas. Dessa forma, vale ressaltar a importância do conhecimento teórico/prático da equipe multiprofissional que acompanha pacientes e familiares em CP. ${ }^{4}$

O termo "home care" significa assistência domiciliar e é definido como cuidado no lar, o qual vem conquistando seu espaço diante dos CP, e muitos familiares de 
pacientes em CP, justamente com a vontade do referido, optam por esse tipo de cuidado, levando em conta que este oferece maior conforto para ambos, esse processo também envolve inúmeros procedimentos hospitalares que por vez, podem ser desenvolvidos no próprio domicílio. ${ }^{5}$ A Atenção Domiciliar (AD) é coordenada pelos Serviços de Atenção Domiciliar (SAD) o qual se inclui na Rede de Atençáo à Saúde (RAS) do Sistema Único de Saúde (SUS), e com base nos princípios e diretrizes do SUS, na SAD deve-se praticar a universalidade, a equidade, a integralidade, a resolubilidade e a ampliaçáo do acesso, em conjunto com a humanização e ao acolhimento. ${ }^{6}$

Destaca-se a importância da realizaçáo do cuidado domiciliar, visto que o mesmo traz inúmeros benefícios, como por exemplo, tempo de internaçáo hospitalar diminuído, aumento no número de leitos hospitalares disponíveis, projeto terapêutico de acordo com os recursos de cada indivíduo e cuidado centrado, entre tantos outros. ${ }^{7}$ O cuidado do paciente em seu domicílio exige uma reorganizaçáo familiar, principalmente quando o familiar é o único cuidador deste, assim, as famílias caracterizadas como provedoras do cuidado, possuem grande notabilidade frente à essa situação do cuidado paliativo domiciliar. $^{8}$

Em um estudo de Souza et al., foi abordado a capacidade dos profissionais da Atenção Primária à Saúde (APS) ao estabelecerem uma situação de vínculo com os pacientes em CP e seus familiares, trabalhando a proximidade de ambos e também a qualificação da assistência que a equipe dispóe, se destacando por terem um perfil diferenciado ao praticarem a inter-relação entre equipe, família e comunidade. ${ }^{9}$

De acordo com a temática cuidado paliativo no domicílio, se faz necessário a abordagem do trabalho em equipe e educação interprofissional, sendo que o trabalho em equipe se constitui em estratégias para que ocorra a interaçáo das múltiplas profissôes e especialidades, nesse caso voltadas a área da saúde. Assim o trabalho em equipe se torna indispensável para o desenvolvimento efetivo da assistência e do cuidado ao paciente. ${ }^{10}$ É de suma importância que todos tenham objetivos em comum para buscarem bons resultados e maior produçáo, tendo sempre em vista a qualidade da assistência prestada.

Segundo a OMS, a educaçáo interprofissional acontece no momento que os estudantes de profissóes diferentes aprendem sobre os outros, com os outros e entre si para proporcionar a colaboraçáo eficaz e aprimorar os resultados na saúde. ${ }^{11}$ A educação interprofissional se propõe a formar profissionais de saúde mais aptos ao efetivo trabalho em equipe. Profissionais colaborativos asseguram práticas em saúde integrais por meio do trabalho colaborativo com maior capacidade de respostas aos problemas e às necessidades de saúde. ${ }^{12} \mathrm{E}$ para que isso ocorra, é preciso que futuros profissionais de saúde, e os que já estão inseridos na realidade do trabalho em saúde, desenvolvam as competências que asseguram a mudança na lógica do modelo de atenção à saúde: a colaboração. 
"Para impactar sobre os múltiplos fatores que interferem no processo saúde-doença, é importante que a assistência domiciliar esteja pautada em uma equipe multiprofissional e com prática interdisciplinar. A interdisciplinaridade pressupóe, além das interfaces disciplinares tradicionais, a possibilidade da prática de um profissional se reconstruir na prática do outro, transformando ambas na intervenção do contexto em que estáo inseridas. Assim, para lidar com a dinâmica da vida social das famílias assistidas e da própria comunidade, além de procedimentos tecnológicos específicos da área da saúde, a valorização dos diversos saberes e práticas da equipe contribui para uma abordagem mais integral e resolutiva" (pág.24). ${ }^{13}$

Frente a esse contexto, destaca-se que o eixo Cuidados Paliativos no Domicílio, faz parte do Programa de Educação pelo Trabalho e para a Saúde - PET Saúdel Interprofissionalidade, do Ministério da Saúde (MS). Esse projeto tem por finalidade integrar ensino-serviço-comunidade, de forma articulada entre o SUS e as instituiçóes de ensino, contando com a parceria da Universidade Regional Integrada do Alto Uruguai e das Missóes - URI Campus Santo Ângelo e a Secretaria Municipal de Saúde do município de Santo Ângelo, estado do Rio Grande do Sul/RS. O projeto PET Saúde/ Interprofissionalidade, conta com cinco eixos de aprendizagem: Gestão em saúde e educaçáo permanente com docentes e trabalhadores do SUS; Cuidados Paliativos no Domicílio; Promoção da saúde junto às comunidades adstritas aos territórios das ESFs; Saúde do trabalhador do SUS; Práticas integrativas no SUS.

Diante disso, o presente estudo se justifica pela necessidade de compartilhar momentos de trabalho interdisciplinar, relatando a produção, bem como a evolução do grupo que busca conhecimentos sobre $\mathrm{CP}$ em domicílio, com o intuito de colaborar com o ensino, serviço e comunidade. Assim, surge a seguinte questáo de pesquisa norteadora: Quais as atividades que o eixo cuidados paliativos no domicílio do PET Saúde/Interprofissionalidade realizou em seus encontros semanais?

$\mathrm{O}$ estudo tem por objetivo relatar a experiência vivenciada pelos integrantes do eixo cuidados paliativos no domicílio do Programa de Educação pelo Trabalho e para a Saúde (PET - Saúde/Interprofissionalidade), tendo ênfase os encontros semanais do grupo.

\section{MÉTODO}

Trata-se de um estudo descritivo com abordagem qualitativa, do tipo relato de experiência. $\mathrm{O}$ estudo descritivo tem a finalidade de apresentar as particularidades de determinados indivíduos ou acontecimentos. ${ }^{14}$ As pesquisas qualitativas, segundo Minayo 15 "se aplica ao estudo da história, das relações, das representaçóes, das crenças, das percepçóes e das opiniões, produtos das interpretaçôes que os humanos fazem a respeito de como vivem, sentem e pensam [...]", contudo a pesquisa qualitativa não se preocupa com números, e sim com conteúdo. 
A experiência dos encontros foi vivenciada por tutores, preceptores, bolsistas e voluntários do Programa de Educação pelo Trabalho e para a Saúde (PET Saúde/ Interprofissionalidade) do eixo cuidados paliativos no domicílio. O grupo de trabalho é composto por três tutoras, docentes da Universidade Regional Integrada do Alto Uruguai e Missões - URI Santo Ângelo/RS; três preceptores (assistente social, enfermeira e psicóloga) profissionais que atuam na secretaria municipal de saúde do município de Santo Ângelo/RS; bolsistas e voluntários que são acadêmicos dos cursos de educaçáo física, enfermagem, farmácia e psicologia da URI Santo Ângelo/RS.

Os encontros ocorriam semanalmente, todas às terças-feiras, em uma sala de aula do prédio 13 da URI Santo Ângelo. As reuniōes possuíam a duração de cerca de duas horas, tendo início às $16 \mathrm{~h} 30 \mathrm{~min}$, com a participação de seus integrantes (tutores, preceptores, bolsistas e voluntários). As reuniōes eram baseadas em leitura e discussão de artigos científicos, análise de textos e vídeos, palestras com profissionais de saúde especialistas em cuidados paliativos, e construção de artigos.

Para os encontros optou-se em utilizar o método roda de conversa. A aplicaçáo da roda de conversa é enfatizada como, um método de discussão que possibilita o aprofundamento do diálogo coletivo e a participação democrática de todos os componentes de um grupo, com base nos conhecimentos e também nas experiências que cada um tem sobre determinado assunto, sendo possível que cada participante expresse sua opiniáo e concepção sobre os temas abordados, bem como, a reflexão frente a cada manifestação apresentada no grupo. ${ }^{16}$

Para Freire ${ }^{17}$ durante a roda de conversa, a pessoa pode interagir e se relacionar com os demais, colocando em prática a capacidade de ensinar e aprender, raciocinar e refletir, bem como, decidir para o bem coletivo. $\mathrm{O}$ autor ainda ressalta que, o objetivo básico do método roda de conversa é fornecer o compartilhamento do conhecimento, valorizando também as experiências. Nos encontros do grupo de cuidados paliativos no domicílio, é notório o quanto esse método é efetivo, pois através do mesmo, os participantes trocam ideias e compartilham vivências. Além disso, a colocaçáo física do grupo em formato de roda possibilita uma melhor visualizaçáo de todos os integrantes, facilitando a conversa e participação de todos.

Os integrantes do grupo também realizaram visita técnica nos serviços de atençấo à saúde do município. Em algumas Estratégia Saúde da Família (ESF) do município realizou-se a análise situacional e visitas domiciliares a pacientes em cuidados paliativos. Também foi organizado pelo grupo, um ciclo de palestras onde foram convidados profissionais de saúde que atuam no cuidado paliativo. Em todos os encontros do grupo foram realizadas fotografias, lista de presença e ata virtual para registro das informaçôes e acontecimentos. 


\section{RELATANDO A EXPERIÊNCIA}

Os encontros eram realizados semanalmente com a finalidade de refletir acerca da temática dos CP. Durante os encontros os integrantes do grupo buscavam aprofundar o conhecimento teórico através do estudo de casos clínicos, leitura e discussão de artigos científicos, livros e outros materiais que abordavam o tema estudado.

Em alguns encontros foram disponibilizados pelas tutoras, artigos científicos sobre os seguintes temas: cuidados paliativos, cuidado domiciliar, espiritualidade, morte, luto, equipe de cuidados paliativos, entre outros. Essa atividade tinha por finalidade propiciar aos integrantes do grupo, a leitura, reflexão e discussão da temática abordada nos artigos científicos. Essas discussóes proporcionaram um melhor entendimento dos assuntos trabalhados nos artigos científicos, pois através da troca de saberes que cada um adquire se formam opinióes diferenciadas, assim como, quando ainda restam dúvidas individuais, o grupo se torna capaz de auxiliar o outro. Sendo que, a leitura e a discussão de artigos são continuamente oferecidas nos encontros do grupo, sempre que surgem novos conceitos a serem trabalhados.

Para contribuir com o aprofundamento teórico da temática dos cuidados paliativos, os integrantes do grupo organizaram um Ciclo de Palestras sobre o tema com a participação de profissionais especialistas na área de cuidados paliativos, sendo duas médicas e uma enfermeira. Essa proposta teve por objetivo alcançar um público maior como tutores, preceptores, professores, acadêmicos e profissionais de saúde do município. Foram organizadas três palestras em datas diferentes, todas na URI - Santo Ângelo/RS. Os temas abordados foram: Comunicação de Más Notícias: É possível falar sobre isso; Cuidados Paliativos em Oncologia e Critérios e Indicaçóes dos Cuidados Paliativos. Nos encontros contamos com a presença significativa de muitas pessoas, o que tornou o evento bem dinâmico, sendo os temas abordados de grande valia para todo o público que se fez presente.

Para um bom desempenho das ações previstas no projeto, efetuamos reflexóes e discussóes também sobre a Interprofissionalidade, a fim de buscar integrar as açóes dos diferentes cursos aos objetivos solicitados no PET Saúde/Interprofissionalidade. Com essa reflexão chegou-se a um consenso de que todas as profissões fazem parte de um grande objetivo, e para chegarmos naqueles objetivos precisamos de todas, cada área com seu conhecimento, tem muito a agregar e ensinar as outras, ao mesmo tempo em que se aprende com todas. A educação interprofissional proporciona aos estudantes a possibilidade de aprendizado em conjunto com outros profissionais para aprimorar as habilidades necessárias em um trabalho coletivo. ${ }^{12}$

Atualmente, a Interprofissionalidade vem conquistando seu espaço junto às políticas de saúde, no Brasil e no mundo, tornou-se considerável inseri-la na gestão do 
trabalho e da educação na saúde, na atividade profissional em equipe e na organização curricular da formação para o trabalho em equipe. O prefixo "inter" indica "no interior de dois", ou seja, na Interprofissionalidade considera-se cruzamento ou encontro de duas ou mais profissóes. ${ }^{18}$ Contudo, para que se possa alcançar o sucesso de uma prática de cuidado ou prática terapêutica, é fundamental que cada profissional saiba distinguir o que não está incluso em seus saberes, mas é domínio de outro profissional.

Realizaram-se também visitas técnicas em alguns serviços de saúde do município, para realização de um diagnóstico situacional dos cenários de prática, por meio da inserçáo de acadêmicos, tutores e preceptores, junto às equipes dos ESFs e Unidades Básicas de Saúde (UBS). O diagnóstico situacional foi realizado em cinco serviços de saúde do município de Santo Ângelo/RS, o que foi de suma importância para o levantamento de informaçóes. Para a realizaçáo da visita nesses locais, dividimos os integrantes do grupo (acadêmicos, tutores e preceptores) em equipes, para que todos tivessem a oportunidade de vivenciar esse momento nos serviços de saúde.

O diagnóstico situacional compreende-se como o resultado de um procedimento de coleta, tratamento e análise dos dados obtidos no local onde se deseja efetuá-lo, através dessa, pesquisa-se as condiçōes de saúde e risco de uma determinada população. A conduta deste visa conhecer a realidade da área estabelecida, bem como diagnosticar problemas, necessidades e situaçóes, e a partir de entáo é possível se estabelecer um planejamento de organização dos serviços de saúde. ${ }^{19}$

Ao realizar o diagnóstico situacional, o grupo tinha como finalidade conhecer o funcionamento da rede, analisar a estrutura física do local, a população que pertence à área de abrangência da unidade, profissionais atuantes no serviço, se a equipe tinha conhecimento sobre $\mathrm{CP}$, se estava acompanhando algum paciente em $\mathrm{CP}$, e qual o número de pacientes que necessitam desse cuidado no domicílio. Para isso, foi construído um roteiro com questóes norteadoras sobre a temática dos $\mathrm{CP}$ e, sobre a rede de atenção, a fim de identificar as condiçóes de saúde e de cuidado na comunidade, bem como as necessidades e carências da equipe acerca da temática.

Para discussão desses pontos realizamos uma roda de conversa com os profissionais de saúde integrantes da equipe, para que todos pudessem se sentir à vontade para dialogar sobre o assunto abordado. As perguntas abordavam a área dos Cuidados Paliativos em domicílio: "Você já ouviu falar sobre os Cuidados Paliativos?", "Se sim, o que é Cuidado Paliativo?", "Você atende algum paciente em Cuidados Paliativos?", "Qual é o diagnóstico desse paciente em Cuidado Paliativo?”, entre outras, e também faziam parte do questionário algumas questôes mais gerais sobre a unidade, como: "Quantos e quais sáo os profissionais atuantes nesta unidade?, Qual área da cidade essa unidade abrange?, Quais os procedimentos são frequentemente realizados nesta unidade?”, entre outras. 
Em estudo realizado com o objetivo de verificar o conhecimento, atitudes e práticas dos profissionais de saúde em relaçáo aos $\mathrm{CP}$, identificou que pouco mais da metade (62\%) dos profissionais relataram que conheciam o tema, e quando questionados sobre a indicação dos CP (89\%) responderam que sabiam quais eram as indicaçôes, e ainda, em relação a abordagem do assunto durante a graduação a maioria (66,7\%) relatou que foi insuficiente. ${ }^{20}$

Diante desse achado, podemos constatar que se mostra extremamente relevante abordar sobre CP com os profissionais de saúde que atuam nos serviços de atenção primária, a fim de que tenham conhecimento acerca do tema, para que, no momento em que se faça necessário acompanhar um paciente em CP, estejam capacitados e atualizados sobre o assunto. Essa capacitação dos profissionais é destacada pelo autor como essencial, e o mesmo também relaciona como:

"Experimentar juntos a dor, o sofrimento, as disputas e tensões entre usuário e familiares, os desejos de cada um, negociar diante dos conflitos, para que se garanta a defesa da vida na iminência da morte" (pág. 100). ${ }^{21}$

Outra ação desenvolvida pelos integrantes do grupo foi a realização de visitas domiciliares nos serviços de saúde do município, com foco na abordagem integral à família e à pessoa em seu contexto socioeconômico e cultural, compromissada com o respeito e a individualidade. O Ministério da Saúde ${ }^{13}$ enfatiza que na atenção domiciliar:

"A equipe deve respeitar o espaço da família, ser capaz de preservar os laços afetivos das pessoas e fortalecer a autoestima, ajudando a construir ambientes mais favoráveis à recuperação da saúde. Essa assistência prestada no ambiente privado das relaçôes sociais contribui para a humanização da atençáo à saúde por envolver as pessoas no processo de cuidado, potencializando a participação ativa do sujeito no processo saúde-doença”" (pág. 22). ${ }^{13}$

Os acadêmicos, juntamente com os preceptores (profissionais de saúde) que atuam nos serviços organizaram pequenos grupos para realizar a visita no domicílio, com o objetivo de adquirir uma vivência nessa área. Através da realização da visita domiciliar os integrantes do grupo puderam vivenciar e refletir desde o processo de acesso ao domicílio (avaliando a acessibilidade do usuário ao serviço de saúde), recepção da família (todas as visitas eram realizadas com agendamento prévio da equipe de saúde), contexto econômico, social e familiar dos usuários, bem como, a relaçáo de vínculo e confiança da família com a equipe.

Frente a esse contexto, destaca-se que as visitas domiciliares são utilizadas no contexto da APS, com o intuito de prestar o atendimento e acompanhamento aos usuários no seu local de residência, porém, contribui para criação de fortes vínculos afetivos com o paciente e seus familiares. ${ }^{22} \mathrm{O}$ acompanhamento do usuário no âmbito domiciliar se destaca por permitir a assistência ao paciente em sua situação de doença no próprio ambiente em que vive dessa forma os profissionais respeitam a autonomia do paciente e 
da família, desenvolvendo um cuidado integral e dispondo de orientaçóes e técnicas que venham a minimizar o sofrimento imposto pela doença. ${ }^{23}$

Quando se trata da assistência prestada ao paciente em cuidados paliativos no domicílio, a equipe deve respeitar os valores culturais e religiosos de cada família e oferecer conforto, carinho, alívio da dor, e preparaçáo como suporte para a morte, diferente disso, o profissional deve rever suas açóes.

Tendo em vista o contexto descrito, afirma-se que, para uma comunicação efetiva entre a equipe multiprofissional e o indivíduo em $\mathrm{CP}$ e seus familiares, é necessário que se estabeleça o vínculo, o qual é proporcionado quando o cuidado além de paliativo é domiciliar. Segundo um estudo de Porto et al., a experiência da equipe, frente ao cuidado no domicílio e o $\mathrm{CP}$, se destaca a comunicação entre os profissionais que resulta em superaçáo de seus sentimentos no cotidiano, como acompanhar o fim da vida de um paciente, percebe-se também, o acolhimento, as trocas de respeito e de afeto, contudo, isso os auxilia e traz sensação de satisfaçáo pelo trabalho em conjunto em prol do paciente. ${ }^{24}$

Todos os assuntos abordados se somam a importância que o grupo construa conhecimento sobre a interprofissionalidade para que desenvolvam uma assistência de qualidade, realizando a escuta e o acolhimento nessa fase pela qual o paciente e seus familiares estão passando, que é o enfrentamento de uma doença incurável envolvendo a fase final da vida.

\section{CONCLUSÃO}

Mostra-se relevante descrever a experiência vivenciada pelos integrantes do eixo cuidados paliativos no domicílio sobre os encontros semanais, a fim de proporcionar o compartilhar de conhecimentos e as construçōes teóricas/práticas desenvolvidas pelo grupo.

Trabalhar com a temática dos cuidados paliativos no domicílio do projeto PET Saúde/Interprofissionalidade, tem sido de grande aprendizado, sendo notório as vivências ímpares proporcionadas aos tutores, preceptores e acadêmicos.

Contudo, destaca-se a relevância de prestar o cuidado paliativo no domićlío por meio de uma abordagem interprofissional, visando a qualidade da assistência, por meio da escuta, diálogo e atenção integral ao usuário e sua família, também vem de encontro à formação profissional, visto que, os acadêmicos em um futuro próximo estarão atuando no mercado de trabalho, através do PET - Saúde/Interprofissionalidade terão uma válida experiência que servirá de amparo diante da atuaçáo profissional. 


\section{REFERÊNCIAS}

1. Rodrigues KM, Felizardo D, Castro EK. Cuidados Paliativos e Espiritualidade no Câncer: um estudo bibliométrico. Rev Nursing. 2019;22(258).Acesso em: 07 abr 2020. Disponível em: http://www.revistanursing.com.br/revistas/258/pg46.pdf

2. OMS, Organização mundial da saúde. Serviços de cuidado paliativo gestão da qualidade. 2002. Acesso em: 07 abr 2020. Disponível em: http://bvsms.saude.gov.br/ bvs/publicacoes/inca/gestao_da_qualidade.pdf

3. Silva ML, Silva RA, SantosACC. Reflexôes Sobre o Fim da Vida: Ética em Cuidados Paliativos. Rev Saúde.2018;12(1). Acesso em: 17 abr 2020. Disponível em: http:// revistas.ung.br/index.php/saude/article/view/3583/2626

4. Conceição MV, Vasconcelos MCC, Telino CJCL, GuedesEVB, Pimentel DMM. Conhecimento Sobre Cuidados Paliativos entre Médicos Residentes de Hospital Universitário. Rev. Bioét.2019;27(1). Acesso em: 07 abr 2020. Disponível em: https:// www.scielo.br/pdf/bioet/v27n1/1983-8042-bioet-27-01-0134.pdf

5. Carnaúba CMD, SilvaTDA, Viana JF, AlvesJBN, Andrade NL, FilhoEMT. Caracterização Clínica e Epidemiológica de Pacientes em Atendimento Domiciliar no Município de Maceió, Estado de Alagoas, Brasil. Rev. Bras. Geriatr. Gerontol.2017;20(3):352-362. Acesso em: 13 jun 2020. Disponível em: https://www. scielo.br/scielo.php?pid=S1809-98232017000300352\&script=sci_abstract\&tlng=pt

6. Braga PP, Sena RR, Seixas CT, Castro EAB, Andrade MA, Silva YC. Oferta e Demanda na Atenção Domiciliar em Saúde. Ciênc. Saúde Coletiva.2016;21(3):903-912. Acesso em: 13 jun 2020. Disponível em: https://www. scielo.br/scielo.php?pid=S1413-81232016000300903\&script=sci_abstract\&tlng=pt

7. Andrade AM, Brito MJM, VonRondow RM, Montenegro LC, Silva KL. Singularidades do Trabalho na Atenção Domiciliar: Imprimindo uma nova Lógica em Saúde. Rev. Pesqui. Univ. Fed. Estado Rio Jan.2013;5(1). Acesso em: 22 abr 2020. Disponível em: http://www.seer.unirio.br/index.php/cuidadofundamental/article/ view/2025/pdf_698

8. Cardoso AC, Noguez PT, Oliveira SG, Porto AR, Perboni JS, Farias TA. Rede de Apoio e Sustentação dos Cuidadores Familiares de Pacientes em Cuidados Paliativos no Domicílio. Rev. Enferm. Foco,2019;10(3): 34. Acesso em: 22 abr 2020. Disponível em: http://revista.cofen.gov.br/index.php/enfermagem/article/view/1792

9. Souza HL, Zoboli ELCP, Paz CRP, Schveitzer MC, Hohl KG, Pessalacia JDR. Cuidados Paliativos na Atenção Primária à Saúde: Considerações éticas. Rev. Bioét.2015;23(2):349-59. Acesso em: 15 jun 2020. Disponível em: https://www.scielo. br/pdf/bioet/v23n2/1983-8034-bioet-23-2-0349.pdf 
10. Peduzzi M, Oliveira MAC, Silva JAM, Agreli HLF, Neto MVM. Trabalho em Equipe, Prática e Educação Interprofissional. Clínica Médica, 2016; 2ª ed..

11. OMS. Organização Mundial da Saúde. Marco para ação em educação interprofissional e prática colaborativa. 2010.

12. Reeves $S$. Why we need interprofessional education to improve the delivery of safe and effective care. Interface.2016;20(56):185-96. Disponível em: https://www.scielo. br/pdf/icse/v20n56/pt_1807-5762-icse-20-56-0185.pdf

13. Brasil. Ministério da Saúde. Secretaria de Atenção à Saúde. Departamento de Atenção Básica. Caderno de atenção domiciliar - Brasília: Ministério da Saúde, 2012. 2v.: il. Disponível em: http://189.28.128.100/dab/docs/publicacoes/geral/cad_vol1. pdf

14. Gil CA. Como Elaborar Projetos de Pesquisa. Atlas. 2008;4.

15. Minayo MCS. O Desafio do Conhecimento: Pesquisa Qualitativa em Saúde.2010;(12).

16. Dias ESM, Rodrigues ILA, Miranda HR, Corrêa JA. Roda de Conversa como Estratégia de Educação em Saúde para a Enfermagem. Rev. fundam. care.2018;10(2): 379-384. Acesso em: 11 mai 2020. Disponível em: http://www.seer.unirio.br/index. $\mathrm{php} /$ cuidadofundamental/article/view/6053/pdf

17. Freire P. Ministério da Saúde. Caderno de Educação Popular e Saúde,2007;32-45.

18. Ceccim RB. Conexões e Fronteiras da Interprofissionalidade: Forma e Formação. SciELO - Saúde Pública. 2018. Acesso em: 11 mai 2020. Disponível em: https://www. scielo.br/pdf/icse/v22s2/1807-5762-icse-22-s2-1739.pdf

19. Silva CSSL, Koopmans FF, Daher DV. O Diagnóstico Situacional como ferramenta para o planejamento de ações na Atenção Primária à Saúde. Revista PróUniverSUS.2016;7(2):30-33.

20. Silva SO, Vidal AS, Oliveira EPC, Morais GSN, Almeida LS, Silva KLB. Conhecimento, Atitudes e Práticas dos Profissionais de Saúde sobre os Cuidados Paliativos a Pacientes Oncológicos. Rev. Eletrônica Acervo Saúde.2019;11(9):1-8. Acesso em: 11 mai 2020. Disponível em: https://acervomais.com.br/index.php/saude/ article/view/369/405

21. Pereira PBA. Atenção Domiciliar e Produção do Cuidado: Apostas e Desafios Atuais. Universidade Federal de São Paulo. 2014;100. Acesso em: 13 jun 2020. Disponível em: https:/www.teses.usp.br/teses/disponiveis/6/6135/tde-01092014111010/pt-br.php 
22. Rocha KB, Conz J, Barcinski M, Paiva D, Pizzinato A. A Visita Domiciliar no Contexto da Saúde: Uma Revisão de Literatura. Psic., Saúde \& Doenças. 2017;18(1). Acesso em: 12 mai 2020. Disponível em: http://www.scielo.mec.pt/scielo. php?script=sci_arttext $\&$ pid $=S 1645-00862017000100015$

23. Silveira CBS, Mafaldo B, Torres OM, Monteiro CE, Balk RS. Atenção Multidisciplinar no Domicílio aos Usuários em Cuidados Paliativos. Salão de Pesquisa.2016;8(2). Acesso em: 12 mai 2020. Disponível em: https://periodicos. unipampa.edu.br/index.php/SIEPE/article/view/90688

24. Porto AR, Thofehrn MB, Dal Pai D, Amestoy SC, Arrieira ICO, Joner LR. Visão dos Profissionais sobre seu Trabalho no Programa de Internação Domiciliar Interdisciplinar Oncológico: Uma Realidade Brasileira. Avances en Enfermería. 2014;32(1). Acesso em: 05 ago 2020. Disponível em: http://www.scielo.org.co/scielo. php?script=sci_arttext \&pid=S0121-45002014000100008\&lang=pt

Autor Correspondente: Lilian Zielke Hesler E-mail: lilianhesler@san.uri.br

Recebido em: 2020-11-30

Aprovado: 2020-12-18 